\title{
Comparison of E-Learning Personalization Systems: Protus and PLeMSys
}

\author{
https://doi.org/10.3991/ijet.v12i01.6085 \\ Nataša Blažeska-Tabakovska \\ University "Sv.Kliment Ohridski", Skopje, Macedonia \\ natasa.tabakovska@fikt.edu.mk \\ Mirjana Ivanović \\ University of Novi Sad, Novi Sad, Serbia \\ mira@dmi.uns.ac.rs \\ Aleksandra Klašnja-Milićević \\ University of Novi Sad, Novi Sad, Serbia \\ akm@dmi . uns . ac.rs \\ Jovana Ivković \\ University of Novi Sad, Novi Sad, Serbia \\ jovana.ivkovic@dmi.uns.ac.rs
}

\begin{abstract}
E-learning is becoming more and more important in contemporary education. It allows learners to learn at their own pace, when their schedule permits it. However, learners have individual needs and different traits such as learning styles, knowledge levels, motivation and cognitive abilities. Therefore, a need for personalized learning has been made clear. Two ways of personalized learning are discussed in this paper: the first is Protus 2.1. - a tutoring system that allows personalization based on learning styles and collaborative tagging and the second one is PLeMSys - a model of a Moodle plug-in where personalization is based on learning styles and knowledge level.
\end{abstract}

Keywords—e-learning, learning management systems, learning styles

\section{Introduction}

Learning courses in a traditional e-learning system consist of lessons presented in a fixed way that is shown to all learners regardless of their learning styles or knowledge level [1]. However, in order for learners to fully utilize the lessons, a degree of personalization is necessary.

Personalized learning refers to a variety of learning experiences, approaches and strategies that address the various learning needs, aspirations, interest and backgrounds of individual learners [2].

Personalized e-learning systems are systems [3] that make effort to adjust the content of a course to fit the needs, interests and talents of learners. 
Moodle e-learning system $[4,5,6]$ is one of the most popular e-learning systems today, due to the ease of creating courses, the potential to make tests, enter grades, adjust layouts, language, not to mention the variety of plug-ins that allow a degree of customization. However, while it does offer many benefits to learners using it, it lacks the ability to personalize content based on learner's needs. So, a plug-in model was developed at the Faculty of Information and Communication Technologies, University of "Sv. Kliment Ohridski", that would fill that need - Personalized Learning Management System (PLeMSys). It would identify learning styles and knowledge levels of learners and customize learning content accordingly.

On the other hand, Protus 2.1. $[3,7,8]$ is a tutoring system used for personalization of the content of the course, based on learners' learning styles. It uses learning styles, knowledge levels, as well as techniques such as collaborative tagging, to personalize the content in a way that matches learners' needs the most. Two co-authors of this paper have had essential role in invention, design, implementation and exploitation of Protus 2.1. system. So they are deeply aware of all essential functionalities, advantages, quality and future upgrades of the system.

With the popularity of Moodle today, it is important to showcase the advantages of using personalization on it, as well as compare the upgraded Moodle with a system specifically, from the beginning designed for personalization. According to previously mentioned facts, we have decided to provide a comparison between these two personalized e-learning systems: PLeMSys, which adds personalization options to Moodle, and Protus 2.1, which has been conceptualized as a personalized learning system. The added similarity is that both systems use the same method for determining learning styles - Felder-Silverman model [9].

The rest of the paper is organized as follows. Section 2 provides an overview of Protus 2.1., its architecture and personalization approaches. Section 3 provides a description of PLeMSys. Section 4 compares the two approaches. Section 5 outlines the conclusion and future work on the presented topic.

\section{Protus 2.1.}

Learners have different preferences and strengths in the way they process and take in information, that is to say, they have different learning styles. Keefe in [10] defines a learning style as a "composite of characteristic cognitive, affective, and psychological factors that serve as relatively stable indicators of how a learner perceives, interacts with, and responds to the learning environment."

Protus 2.1. is an e-learning system designed for personalization based on learning styles.

It is an interactive system whose goal is presentation of learning material to learners, as well as testing their acquired knowledge. 


\subsection{System Architecture}

The architecture of Protus 2.1 enables the development of courses in three different phases:

- creating a skeleton of the course using the Vaadin Java framework [11],

- creating courses, all the material pertaining to them, as well as a test for each lesson and

- presenting the personalized learning material to a learner.

These phases are shown in Fig. 1. The figure also shows that there are three separate user roles: system administrator that maintains the application, teachers who create and maintain courses, and learners.

All courses follow the same learning process that consists of monitoring learners' activities, developing the learner model and personalizing the content.

Courses in Protus 2.1 are split into lessons. Each lesson consists of materials presented in different ways in order to facilitate personalization - introduction, explanation, syntax diagrams, examples, practical assignments, etc. as well as tests to use as a benchmark for learners' progress. When the learner completes the sequence of learning contents, the system evaluates the learner's knowledge degree. The test contains several multiple-choice questions and code completion tasks. Protus 2.1 then provides feedback to the learner on his/her answers and gives the correct solutions after the test. Further, recommendation process i.e. recommendation of learning material that has to be used in next step is carried out using the collaborative filtering approach, described in [3]. Teaching material, described concepts and architecture are shown in Fig. 2.

Protus 2.1 is fully implemented using Java and Vaadin framework. An example of a lesson stored in Protus 2.1 is shown in Fig. 3. While Protus 2.1 had been designed as a general programming tutoring system, only a Java course is currently available. The course has been tested and it is fully functional.

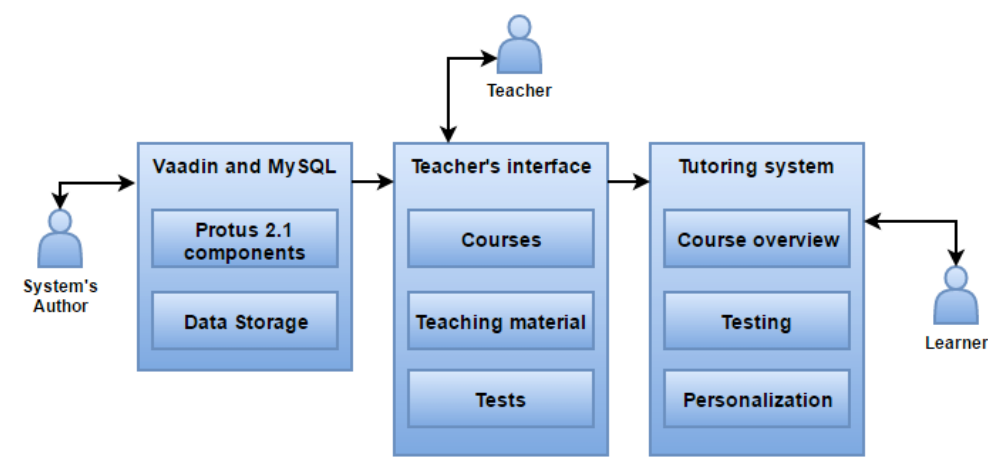

Fig. 1. Development of courses in three phases 


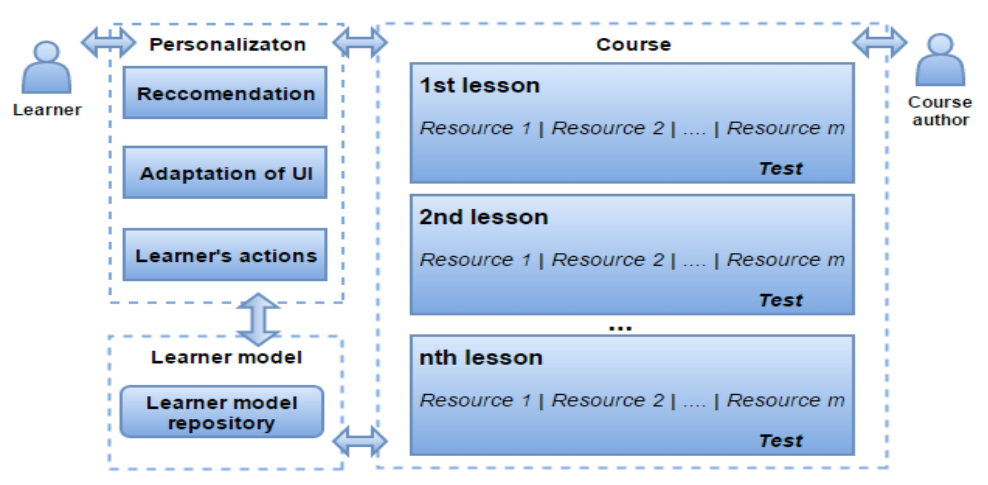

Fig. 2. Teaching material in Protus 2.1

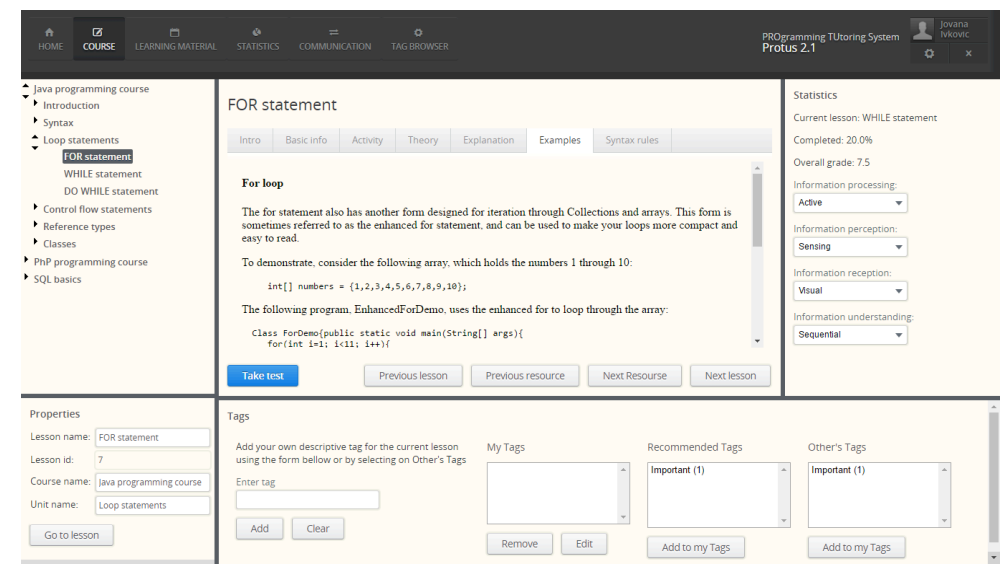

Fig. 3. An example of a lesson stored in Protus 2.1

\subsection{Adaptive Learning and Personalization in Protus 2.1}

Different techniques need to be implemented to adapt content delivery to individual learners according to their learning characteristics, preferences, styles, and goals. Three different levels of personalization, suggested in literature [12], are involved in Protus 2.1 system: self-described personalization, segmented personalization and cognitive-based personalization.

- Self-described personalization. The learners describe their preferences and common attributes with use of questionnaire, as well as identify their backgrounds and previous experiences. These create the initial learner model. Protus 2.1 needs than to track learner's achievement and update learner model accordingly.

- Segmented Personalization. Learners are grouped into smaller, identifiable and manageable clusters, based on their learning styles. Parts of the appropriate materi- 
al and instruction are then tailored to the groups, and are applied in the same or similar way to all members of a segmented group.

- Cognitive-based personalization. Cognitive-based personalization represents process of adapting and delivering content and instruction to specific types of learners, defined according to information about their capabilities, learning style and preferences. These may include, for example: a learner's preference for specific type of tests or tasks, or linear sequencing over grouping of hyperlinks, as well as recognition of the learner's reasoning capacity and capability for inductive reasoning. This type of personalization requires collecting data, monitoring the learner's activities, comparing it to other learners' behavior, building a learner model and predicting and recommending what the learner would like to do or see next.

\subsection{Learning Styles}

In order to present learning material in a personalized way it is necessary to determine learning style of a learner. Learning style of a learner is important during learning process and presentation of learning content in such a way that it is most appropriate for particular learner. In fact, some learners prefer to see and use learning materials, organized in visual manner with a lot of pictures, diagrams, flow-charts. On the other hand, some learners prefer textual form of learning material. As a result, in order to present learning material to a learner in style that is most appropriate to $\mathrm{him} / \mathrm{her}$, it is necessary to determine his/her learning style. There are a lot of instruments to do it and a data collection instrument, called the Index of Learning Styles ILS [9], was used in our case. ILS consists of 44 questions that help determine individual learning style preferences across four domains. Those domains are Information Processing, Information Perception, Information Reception and Information Understanding.

- Information Processing: active and reflective learners. Active learners learn through action, efforts, working with others, while reflective learners learn through collecting data and analysing it and acting alone.

- Information Perception: sensing and intuitive learners. Sensing learners need concrete, practical examples and are oriented towards facts, while intuitive learners learn best through conceptual means and theoretical knowledge.

- Information Perception: visual and verbal learners. Visual learners prefer a visual representation of the content through images, diagrams, charts, while verbal learners prefer written content or verbal explanations.

- Information Understanding: sequential and global learners: sequential learners learn best in consistently small steps, while global learners learn best in larger units.

The user interface in the Java programming course, stored and organized in Protus 2.1 system, is adapted based on a learner's learning style in the following ways: 
- A learner with an active learning style is shown an activity first, then a theory, explanation and example, while a reflective learner needs to have the resources presented in a different order: example, explanation, theory and finally, an activity.

- Sensing learners have additional material within each lesson on which they may click on any time, while intuitive learners are provided with abstract material, formulas and concepts, while explanations are given to them in form of block diagrams or exact syntax rules.

- Verbal learners are shown i.e. detailed explanation of a syntax rule, while visual learners are shown block diagrams.

- - Sequential learners go through lessons in a predefined order, while global learners are provided with an overall view of the course in advance, with a short explanation of each lesson and then they can arbitrarily move through the course.

Different researches $[13,14]$ have shown that learning style may change depending on the task that the learner has mastered. Also, learning style may be changed according to the content and duration of learning. Therefore, it is counterproductive to leave the learner's learning style unchanged throughout the whole course, especially if the learner is not further satisfied with current learning style. According to this for the rest of the course, learners could freely switch between presentations methods and styles by using the experience bar in Fig. 4. Regarding that learning style may change depending on the task that the learner has mastered and also according to the content of learning, Protus 2.1 enables learners to choose the presentation method that suits them the best. After using system some time and learning -according to pre-determined learning style, learner may conclude that this style is not any more appropriate to $\mathrm{him} / \mathrm{her}$. So learner can explicitly change his/her learning style using the experience bar.

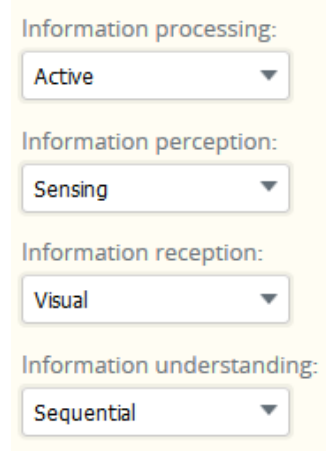

Fig. 4. Experience bar

Protus 2.1. has brought an improvement to the previous versions of the system applying tag-based recommendations [15]. It allows learners to tag the resources in the course. Tags are used to combine the concept of tutoring systems with the collaborative tagging methods [16]. There are two expected benefits of using collaborative tagging with learning resources [17]. Firstly, resource metadata can be improved with 
learners' tags, tags that reflect their way of describing, classifying and locating educational material, which leads to personalized search and recommendation of further resources. Secondly, it offers alternative ways of classifying and retrieving educational resources based on folksonomies.

\section{$3 \quad$ PLeMSys}

One of the most popular and frequently used e-learning system Moodle $[4,5,6]$ is developed with both pedagogy and technology in mind. Moodle can be used in many types of environments such as in education, training and development, and business settings [5]. This e- learning platform has several typical e- learning features, plus some original innovations (like its filtering system) [18].

However, Moodle offers limited support for personalization: in terms of user interface, it is possible to personalize the environment by creating new themes, and, in terms of features, users can add a number of plug-ins available on the Moodle official website [3]; however, from a methodological point of view, its potential in personalization is limited [19].

Personalization is possible in two ways: personalizing the way the content is presented to a learner and personalizing the access to the content of the course.

Personalization process of PLeMSys, as suggested by the Faculty of Information and Communication Technologies, University of "Sv. Kliment Ohridski", follows these steps:

1. Data collection - data is collected from various sources (course entrance test, questionnaires to determine learning style, finals module test, time spent on different formats during previous experiences with PLeMSys)

2. Data processing - the collected data is processed in order to obtain a form necessary for the next step

3. Pattern detection - the data is analysed in order to determine the relationship between the data and the learning patterns. At this stage the following methods are used: clustering, association rules, patterns of connectivity

4. Personalization - In order to effectively personalize the content and manner of presentation, the following tasks are necessary [20]:

(a) task of prediction - which is in charge of a special unit. This unit according the previous learner experience with the system, predict some uncertain elements

(b) task of selection - the model is in charge of selecting the most interesting/useful content for a learner

5. In the proposed model shown in Fig. 5 the key elements are: creation of three different forms of the same curriculum content for each lesson L, from each individual module $\mathrm{M}$, for each course $\mathrm{C}$ and determining the preference of the user.

6. Before starting the course, the learner fills in the questionnaire based on the FelderSilverman model of learning [9]. Based on the results of the questionnaire, learners are separated in three categories of learning styles that they prefer, which can be seen in Table 1. For each learner it is important to discover his/her learning style as the same learning material is prepared in different ways to fulfill requirements of 
particular learning style. It means that the same lesson will be prepared in three forms, one form for each learning style. So, for example, to learner who prefer visual type of learning multimedia form of the lesson will be presented.

The organization of lessons in the course are shown in Fig. 6. Within each module $\mathrm{M}_{1}, \mathrm{M}_{2}, \ldots \mathrm{M}_{\mathrm{n}}$, lessons have a suggested order, and are indexed according to it, i.e. the lessons of module $\mathrm{M}_{1}$ are $\mathrm{L}_{11}, \mathrm{~L}_{12}, \ldots, \mathrm{L}_{1 \mathrm{~m}}$. Each lessons have three formats, so lessons are actually indexed as follows (with the example of the lessons $\mathrm{L}_{11}$ ): $\mathrm{L}_{11 \mathrm{ml}}, \mathrm{L}_{11 \mathrm{tl}}$ and $\mathrm{L}_{11 \mathrm{pl}}$ according to table 1 . Each module includes an input test $\mathrm{T}_{\mathrm{i} 0}$ and a final test $\mathrm{T}_{\mathrm{i} 1}$. Test results are saved in the system and present a part of a learner's profile.

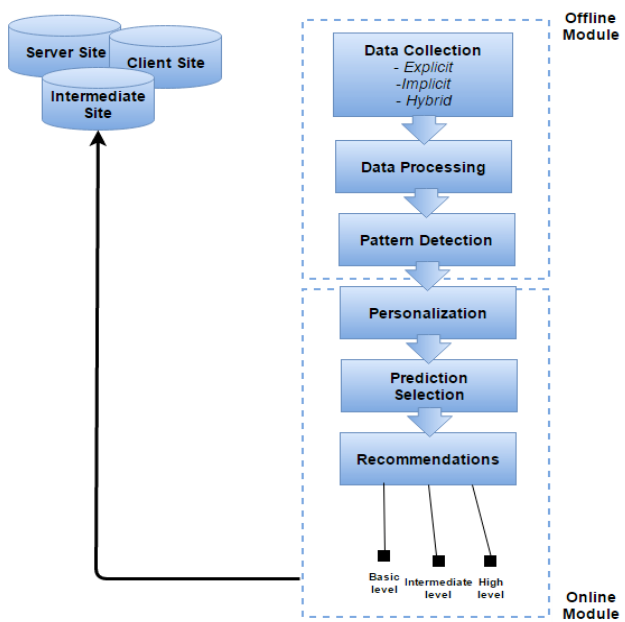

Fig. 5. Proposed model of PLeMSys

Table 1. Learning styles and lesson formats

\begin{tabular}{|l|c|c|}
\hline Group & Learning Style & Content Format \\
\hline 1 & Visual, Sequential, Reflective & Multimedia lessons $m l$ \\
\hline 2 & Verbal, Intuitive, Reflective & Theoretical lessons $t l$ \\
\hline 3 & Sensory, Active, Global & $\begin{array}{c}\text { Lessons based on } \\
\text { practical examples } p l\end{array}$ \\
\hline
\end{tabular}

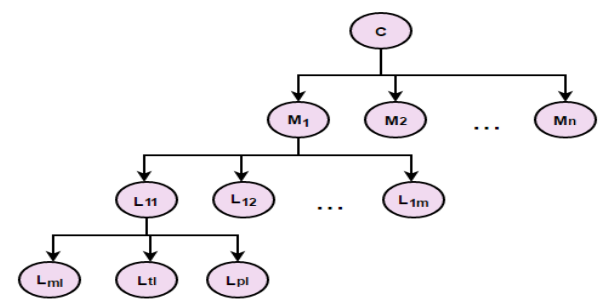

Fig. 6. Graph showing lesson organization 


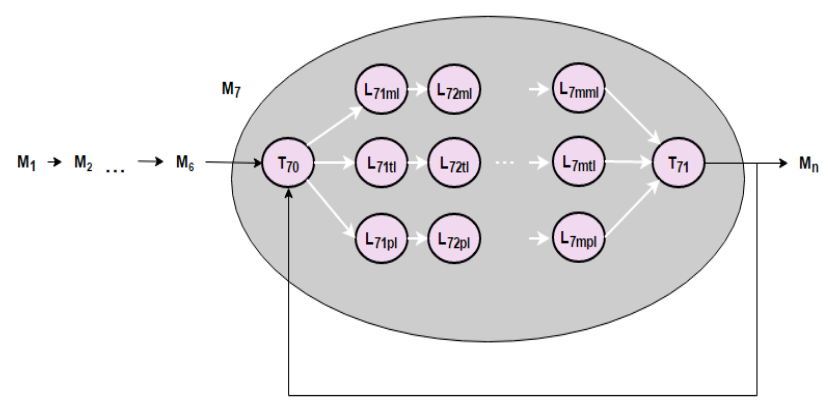

Fig. 7. Graph showing course progression for learners with basic level of knowledge

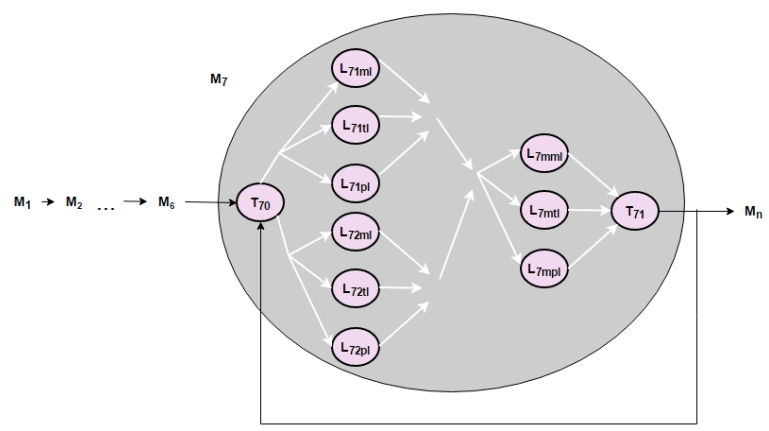

Fig. 8. Graph showing course progression for learners with intermediate level of knowledge

Additionally, preferred format of a lesson can be determined based on time spent on different formats during previous experiences with PLeMSys. That of course, hinges on the learner using the system for a longer period of time so that the necessary data can be collected. The time itself would be measured using a Moodle plugin, Timestat [21].

Next step is to determine the knowledge level of a learner, achieved through a course entrance test. Based on the results, learners' knowledge can be categorized as:

- basic level of knowledge

- intermediate level of knowledge

- high level of knowledge

Based on knowledge levels, learners will move throughout the course in different ways. However, it doesn't impact their learning style, as it was determined by the questionnaire.

Learners who belong to the group with a basic level of knowledge must follow the lessons in the given order. The graph that illustrates their progression through the course is shown in Fig. 7. The entrance test for each module serves as the basis for measuring learners' progress. Further navigation through the module depends on the results of the module's final test. A learner cannot progress to the next module without successfully completing the previous one. 
Learners with intermediate level of knowledge can arbitrarily move through lessons in the module, as shown in Fig. 8. In order to progress to the next module, they must pass the previous module's final test.

The last group consists of learners with high level of knowledge. These learners can move though different modules and lessons within the modules completely arbitrarily, as shown in Fig. 9. They only take the course entrance and final test, not the thematic tests of the modules.

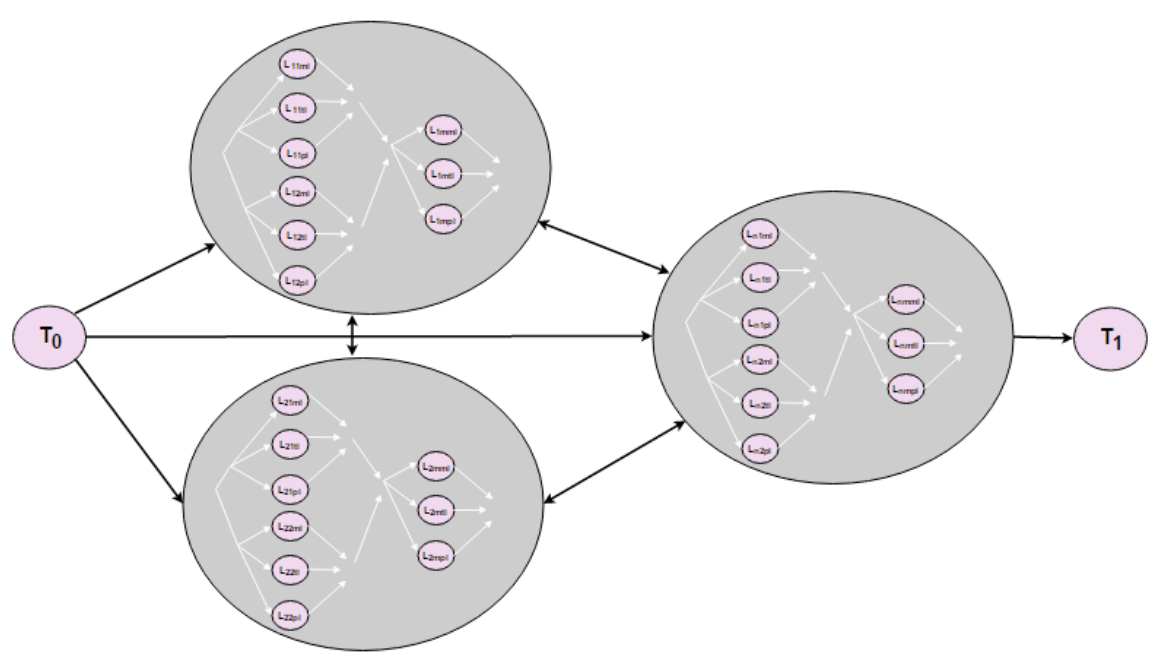

Fig. 9. Graph showing course progression for learners with high level of knowledge

\section{Comparison}

Both Protus 2.1. and PLeMSys, independently developed, use similar ideas for personalization: determining the learning style of the learners using the Felder-Silverman model of learning, and then customizing the content of the course. However, at this point the separation occurs. Protus 2.1 differentiates amongst all of the learning styles (i.e. based on the learning styles there are 16 different ways of displaying the content of the course), while PLeMSys groups learning styles and shows the content in 3 distinctive styles (multi-media, theoretical and practical lessons). Also, learners in Protus 2.1 can change the presentation model at any time, as learning style preference may change in regards to the content or knowledge level.

PLeMSys explicitly personalizes based on the knowledge level (as determined by the tests in each module). Protus 2.1 does have tests in each module, but it doesn't explicitly separate the learners based on the results. It would be beneficial to use personalization based on knowledge level of learners in Protus 2.1 as well, by analysing the results of learners with different learning styles.

Since PLeMSys is meant for the Moodle learning system, it has all the features that Moodle system can offer, as well as all the plug-ins created by the Moodle communi- 
ty that allow customization. One of the benefits is the advantage of adding new lessons through the web application. While Protus 2.1 does offer it to the teachers/course creators, it is a part of the desktop application, and not yet available online.

Protus 2.1 was conceptually created for programming courses, as its name implies, while PLeMSys is applicable in general subjects as well.

One of the advantages of Protus 2.1 is its adaptability. Since it was built from the ground up, any changes in the functionalities of the system can be made, while PLeMSys depends of Moodle itself.

And lastly, Protus 2.1 is implemented and fully functional, while PLeMSys is at the moment at the conceptual level and has yet to be implemented for real use.

\section{Conclusion}

Personalization of the e-learning system improves the quality of the system itself [3] and allows learners to learn in a style that most suits them. Generally speaking, experiments that we performed with our learners using Protus 2.1. that facilitate personalization in Java programming course, showed several advantages. Teaching material has been prepared for different learning styles and learners have used a particular form of materials adjusted to their learning style. We achieved the following optimistic results:

- The majority of learners were extremely motivated to use Protus 2.1. since the material was attractive and the presentation was more friendly and clear.

- Accordingly, they were more involved in teaching/learning processes and gave us valuable feedback about presented material. We will use them to further improve existing material.

- Results, gained knowledge and final grades that learners achieved using the system, were higher compared to several previous generations of learners.

In this paper, we have compared two independent approaches to personalization in e-learning: Protus 2.1., a fully implemented tutoring system that uses learning styles and collaborative tagging to personalize the content of the course according to the needs of a learner, and PLeMSys - a conceptual model for a Moodle plug-in, which also bases its personalization on learning styles, but uses knowledge levels of learners in the process, as well.

By comparing Protus 2.1 and PLeMSys, we are also comparing the advantages of a system designed for personalized learning versus the advantages of a plug-in that allows personalization in an established learning system.

PLeMSys identifies three ways of presenting the information (multimedia, theoretical and practical) based on learning styles, while the order of the lessons depends on the knowledge level of a learner. On the other hand, Protus 2.1 takes into account all the possible combinations of learning styles, as well as collaborative tagging. Protus 2.1 also allows learners to switch the presentation mode if their preferences change. So, while the core idea was similar (identifying learning styles using the same test), the execution differs. 
This paper also shows that while personalization might be a common goal to which an e-learning system strides towards, there is a broad spectrum of possible ways of achieving it.

The comparison is a good basis and motive for the research we plan to conduct - an experimental comparison of the two describes systems in order to determine:

- Which system has the superior learner interface?

- Which system provides the most desired functionality?

- Which system has a more successful learning curve?

- Which system do the learners prefer?

In addition, we plan to analyze the systems' characteristics, expected in the case of potential unlimited learners' participation and open access via the web.

\section{References}

1. M.J. Rosenberg, E-learning: Strategies for delivering knowledge in the digital age, vol. 2. New York: McGraw-Hill, 2001

2. The glossary of education reform, http://edglossary.org/hidden-curriculum

3. A. Klašnja-Milićević, B. Vesin, M. Ivanović, andZ. Budimac,"E-Learning personalization based on hybrid recommendation strategy and learning style identification,"Computers \& Education, vol. 56, pp. 885-899, April 2011. https://doi.org/10.1016/j.compedu. 2010.11.001

4. Moodle e-learning system, https://moodle.com/

5. C.C. Su, "An open source platform for educators," Fifth IEEE International Conference on Advanced Learning Technologies (ICALT'05), pp. 961-962,July 2005.

6. A. Al-Ajlanand H. Zedan, 2008, October. "Why moodle," Future Trends of Distributed Computing Systems, pp. 58-64, October 2008.

7. B. Vesin, A. Klašnja-Milićević, M.Ivanović andZ. Budimac,“Applying Recommender Systems and Adaptive Hypermedia for e-Learning Personalization,"Computing and Informatics, vol. 3, pp. 629-659, October 2013.

8. B. Vesin,M. Ivanović, A. Klašnja-Milićević, and Z. Budimac, "Protus 2.0: Ontology-based semantic recommendation in programming tutoring system," Expert Systems with Applications 39, vol. 15, pp. 12229-12246, November 2012.

9. R.M. Felder, and B. A. Soloman. "Index of learning styles (ILS)." On-line at http://www4.ncsu.edu/unity/lockers/users/f/felder/public/ILSpage.html, 1999.

10. J.W. Keefe, "Learning style: An overview", Student learning styles: Diagnosing and prescribing programs, pp. 1-17, 1979.

11. M. Grönroos, Book of Vaadin, Lulu. com, 2011.

12. R. C. Clark \& R. E. Mayer, E-learning and the science of instruction: Proven guidelines for consumers and designers of multimedia learning, John Wiley \& Sons, 2016. https://doi.org/10.1002/9781119239086

13. H.J. Yazici, "Role of learning style preferences and interactive response systems on student learning outcomes." International Journal of Information and Operations Management Education 6, vol. 2, pp. 109-134, 2016.

14. F. Coffield, D. Moseley, E. Hall, and K. Ecclestone,Learning styles and pedagogy in post 16 learning: a systematic and critical review, The Learning and Skills Research Centre, 2004. 
Paper-Comparison of E-Learning Personalization Systems: Protus and PLeMSys

15. A. Klašnja-Milićević, B.Vesin, M. Ivanović, and Z.Budimac. "Personalisation of Programming Tutoring System Using Tag-Based Recommender Systems," In 2012 IEEE 12th International Conference on Advanced Learning Technologies, pp. 666-667, July2012.

16. H.H. Kim, "A personalized recommendation method using a tagging ontology for a social e-learning system." In Asian Conference on Intelligent Information and Database Systems, Springer Berlin Heidelberg, pp. 357-366, April 2011. https://doi.org/10.1007/978-3-64220039-7 36

17. P. Zervas, D.G. Sampson, "The effect of users' tagging motivation on the enlargement of digital educational resources metadata", Computers in Human Behavior,vol 32, pp. 292300, 2014. https://doi.org/10.1016/j.chb.2013.06.026

18. A. Toth, P. Pentelenyi, and P. Toth, Virtual Learning Aspects of Curriculum Development in Technical Teacher Training, in Proceedings of Intelligent Engineering Systems, IEEE, London, UK, 2006. https://doi.org/10.1109/ines.2006.1689389

19. C. Limongelli, F.Sciarrone, and G. Vaste, "Personalized e-learning in Moodle: the Moodle_LS System," Journal of e-Learning and Knowledge Society 7, vol. 1, January 2011.

20. G. Castellano and A.M.Fanelli, eds, Web Personalization in Intelligent Environments' Vol. 229, Springer, 2009.

21. Timestat plug-in, https://moodle.org/mod/data/view.php?d=13\&rid=4200

\section{$7 \quad$ Authors}

Nataša Blažeska-Tabakovska graduated at the Faculty of Natural Sciences, Department of computer science, University of "St. Kiril i Metodij" - Skopje, Republic of Macedonia, and received the professional title: graduate engineer of mathematicsinformatics. She finished her master degree studies at the Faculty of Education, "St. Kliment Ohridski" University in Bitola, R. Macedonia, and she received her $\mathrm{PhD}$ degree in Information systems management at the Faculty of Administration and Information Systems Management, "St. Kliment Ohridski" University in Bitola, R. Macedonia in 2013. Her current position is Assistant professor at the Faculty of information and communication technologies, "St. Kliment Ohridski" University in Bitola, R. Macedonia. Her research interests include: knowledge management systems, experts systems, LMS, e-learning and system analysis and design. (e-mail: natasa.tabakovska@fikt.edu.mk)

Mirjana Ivanović holds the position of Full Professor at Faculty of Sciences, University of Novi Sad. She is a member of the University Council for Informatics. She is author or co-author of 13 textbooks and more than 330 research papers on multi-agent systems, e-learning, and intelligent techniques, most of which are published in international journals and conferences. She is/was a member of Program Committees of more than 200 international conferences, leader of numerous international research projects. Mirjana Ivanović delivered several keynote speeches at international conferences, and visited numerous academic institutions all over the world as visiting researcher. Currently she is Editor-in-Chief of the Computer Science and Information Systems journal. (mira@dmi.uns.ac.rs).

Aleksandra Klašnja-Milićević is an assistant professor at Faculty of Sciences, University of Novi Sad, Serbia. She graduated at the Faculty of Technical Sciences, University of Novi Sad, Department of Electrical Engineering and Computer Science, 
receiving a B.Sc. degree in 2002. She joined the graduate program in Computer Sciences at Faculty of Sciences, Department of Mathematics and Informatics, University of Novi Sad in 2003, where she received her M.Sc. degree (2007) and PhD degree (2013). Her research interests include e-learning and personalization, Intelligent Tutoring Systems, information retrieval, Internet technologies and recommender systems. She actively participates in several international projects. She has also served as Program Committee member of several international conferences. She co-authored one university textbook and one monograph. She has published over 30 scientific papers in proceedings of international conferences and journals. (akm@dmi.uns.ac.rs)

Jovana Ivković is an assistant at the Faculty of Science, University of Novi Sad, Serbia. She graduated at the Faculty of Science, receiving B.Sc. and M.Sc. degrees in Computer Science in 2013 and 2015, respectively. She joined the graduate studies at the same faculty, and is working towards her $\mathrm{PhD}$ degree. She is a participant of several international projects. Her research interest include artificial intelligence, multiagent systems in particular, as well as e-learning. (jovana.ivkovic@dmi.uns.ac.rs)

Submitted, 28 July 2016. Published as resubmitted by the authors on 11 November 2016. 